LETTER TO JMG

\title{
Constitutional rearrangements of chromosome 22 as a cause of neurofibromatosis 2
}

\author{
T Tsilchorozidou, F H Menko, F Lalloo, A Kidd, R De Silva, H Thomas, P Smith, A Malcolmson, \\ J Dore, K Madan, A Brown, J G Yovos, M Tsaligopoulos, N Vogiatzis, M E Baser, A J Wallace, \\ D G R Evans
}

$\mathrm{N}$ eurofibromatosis type $2(\mathrm{NF} 2)$ is an autosomal dominant condition characterised by vestibular schwannomas, schwannomas of other cranial nerves, meningiomas, and other low grade brain malignancies. ${ }^{1}$ The severity of NF2 is variable, with some patients having early onset disease and more rapidly growing tumours that occur in greater numbers. The NF2 gene is on chromosome 22q12. ${ }^{23}$ The protein product (termed merlin or schwannomin) is a cell cytoskeleton associating protein. Genotype-phenotype correlations have been demonstrated, with missense mutations and large deletions causing mild disease, and nonsense or frameshift mutations causing severe disease. ${ }^{45}$

The current mutation screening techniques of single strand conformation polymorphism analysis (SSCP), protein truncation test, and denaturing gradient gel electrophoresis detect $33-65 \%$ of mutations, although adding a deletion strategy increases the proportion to $80 \% .{ }^{6}$ However, deletion testing and chromosome analysis are rarely reported in studies of NF2 mutations. In this study, we present five NF2 patients for whom chromosome analysis, usually following routine molecular screening, revealed the underlying genetic aberration.

\section{CASE REPORTS}

\section{Case 1}

A 20 year old female was referred with a large diffuse goitre commencing early in puberty, moderate learning difficulties, and bilateral sensorineural hearing loss, which resembles the phenotype of Pendred's syndrome. She was born after a normal pregnancy and delivery. Her physical and mental development during early infancy was not remarkable, but developmental delay became apparent in the second year of life. Growth parameters were within the normal range. She began to walk at the age of 3 years. Six months later, audiometric tests showed no hearing impairment although chronic otitis media was diagnosed on one side. According to the parents, her communication had been improving with age, but her speech remained dysarthric and her articulation was very poor. In primary school, she had sub-average grades in all subjects. Her affect was good and no behavioural problems had been noticed. Psychometric evaluation with PMS-T (Raven) WAIS and Bender Gestalt tests showed severe mental impairment (IQ of 40).

Her clinical features included a round face with characteristic almond shaped eyes (doe eyes). Her weight was $78 \mathrm{~kg}$, height $172 \mathrm{~cm}$, and body mass index 26.5. There was bilateral pes cavus but no other dysmorphic features or organ anomalies were observed. She was left handed. She was in good health and there was no history of neurological illness. There were no peripheral stigmata of neurofibromatosis.

The goitre appeared soon after puberty. Thyroid hormone levels constantly remained in the normal range, but thyroid

\section{Key points}

- We present five previously unreported neurofibromatosis type 2 (NF2) patients who have gross constitutional rearrangements involving chromosome 22, and vestibular schwannomas, multiple intracranial meningiomas, and spinal tumours.

- Three female patients with $46, X X, r(22)$ had moderate to severe intellectual impairment, vestibular schwannomas, and multiple meningiomas.

- A male patient with $46, Y, \operatorname{der}(X)(22 q t e r \rightarrow q 13:: X p 22.3 \rightarrow$ Xqter), $r(22)(p 13 \rightarrow q 13)$ presented at the age of 18 years with a large vestibular schwannoma but no other symptomatic clinical abnormalities. The karyotype suggested disruption of SHOX and a radiological assessment confirmed features of dyschondrosteosis.

- A female patient with an apparently balanced translocation $46, X X, t(1 ; 22)(p 36.1 ; q 12)$ had skin nodules at 7 years of age and multiple intracranial tumours at 20 years.

- An additional 10 NF2 patients with constitutional NF2 deletions have been discovered using NF2 FISH in our laboratory. At least six other NF2 patients with chromosomal rearrangements have been previously reported in the literature.

- Chromosome analysis with FISH may be a useful first screen prior to molecular testing in NF2 patients.

volume progressively increased despite the administration of levothyroxine at thyroid stimulating hormone suppressive doses (100 $\mu \mathrm{g} /$ day). Unfortunately, a perchlorate discharge test, which could confirm an iodide organification defect, was not carried out because total thyroidectomy was performed in another hospital soon after her visit to clinic. The main reason for surgery was cosmetic. Histological examination showed a colloid goitre (about $71 \mathrm{~g}$ in weight) without signs of malignancy. There was no history of NF2 or thyroid disease in the maternal or paternal family.

No radiological malformations were found in the inner ear structure. In particular, no Mondini cochlea or enlarged vestibular aqueduct was seen on high resolution computed tomography (CT) of the petrous temporal bones, and no membranous labyrinth alterations (endolymphatic duct and

Abbreviations: $C T$, computed tomography; $M R I$, magnetic resonance imaging; NF2, neurofibromatosis type 2; SSCP, single strand conformation polymorphism analysis 


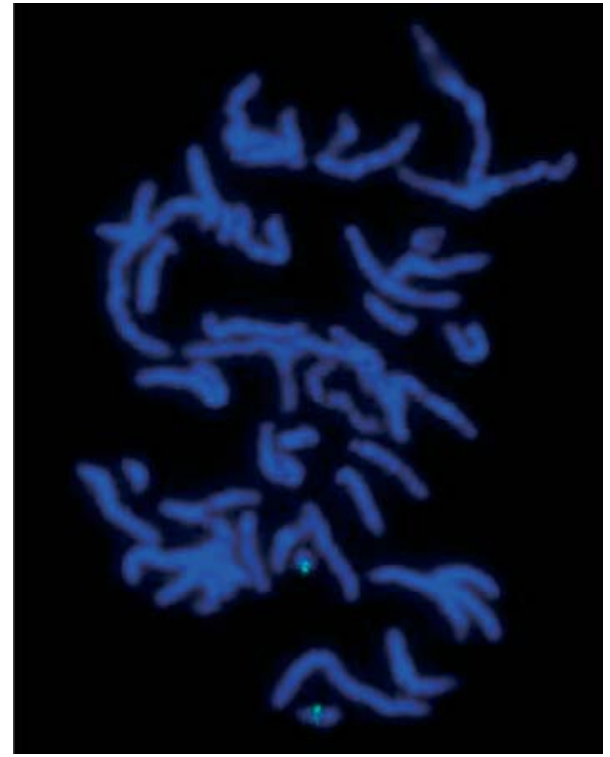

Figure 1 Metaphase spread of case 1 showing 46,XX,r(22). FISH analysis showed the NF2 locus present on the ring chromosome 22.

sac) were detected on an FSE T2 weighted magnetic resonance imaging (MRI) scan. A large vestibular schwannoma on the left side expanded the cerebellopontine angle, and there was a small right sided tumour. There were multiple intracranial meningiomas (parietal, occipital, and cerebellar) and at least four intraspinal extramedullary, extradural tumours at the level of T6 and T7.

Cytogenetic analysis was performed on peripheral blood lymphocytes using FISH. The constitutional karyotype of the patient was $46, \mathrm{XX}, \mathrm{r}(22)$ and the NF2 locus was present on the ring chromosome 22 (fig 1). The ring 22 was present in most cells analysed. No mutation was found on molecular screening with direct sequencing of all exons, or on dosage PCR of exons $1,4,8$, and 15 .

\section{Case 2}

A 52 year old female resident of a community psychiatric care home was referred for management of epilepsy in 1998. The history was provided by a carer who had known the proband for 9 years. It was reported that the patient had developed seizures for the first time a year previously. In all three episodes, generalised convulsions had been witnessed. She had had severe learning disability from birth and communicated by making noises. She was known to have cyclical mood swings, and these had become more pronounced over the preceding year. She also appeared to be suffering from headaches. She was subdued when examined, had no "focal" neurological deficits, and had some catatonic posturing. Her general examination revealed gross bilateral lower limb lymphoedema, but was otherwise unremarkable. In particular, she had no cutaneous signs of neurofibromatosis.

Axial cranial CT revealed multiple calcified mass lesions, the largest in the right middle cranial fossa and several around the falx and adjacent to the skull vault, consistent with meningiomata. There was evidence of bilateral cerebellopontine angle masses, the right being larger than the left A degree of cerebral atrophy was also present. She was evaluated by a neurosurgeon who felt that there was no indication for surgical treatment. She was readmitted several months later with status epilepticus and probable aspiration pneumonia, and died shortly thereafter. Permission for autopsy was not sought.
There is little information on the patient's past medical and developmental history. She underwent a hysterectomy in 1992 for removal of pleomorphic leiomyomas. The histology of these tumours showed bizarre cellular and nuclear pleomorphism, hyperchromatic nuclei, and multinucleated forms, but no increase in mitotic figures. There was no family history to suggest NF2.

Cytogenetic analysis was performed on peripheral blood of the patient and her two brothers using PHA lymphocyte cultures. The majority (47/50) of cells in the proband had one of the chromosome 22 homologues present in the form of a ring chromosome. The remaining three cells had lost the ring chromosome, and were monosomic for the whole of chromosome 22. In situ hybridisation studies to localise the breakpoint on the long arm of chromosome 22 showed that the missing part of the chromosome did not extend as far as the NF2 locus. There was no deletion of the Di George/ VCFS locus at 22q11.11. However, a probe for the arylsulphatase A gene, ARSA, located terminally at 22q13, was deleted on the ring chromosome. The karyotype was 46,XX,r(22).ish r(22)(pl lql3)(TUPLEl+,10H11+,ARSA-)(47)/ $45, X X,-22(3)$. Chromosomal analyses on both brothers were normal. Mutation analysis of the NF2 gene in blood lymphocytes did not reveal an abnormality.

\section{Case 3}

An institutionalised woman presented at 39 years of age with multiple meningiomas and a right sided vestibular schwannoma. She had "developmental delay from infancy" and no family history of NF2 or learning difficulties. The patient walked at 21 months and had little speech at 3 years. By 9 years of age she could read and write and do simple sums. She had large eyes with wide palpebral fissures, short smooth philtrum limited speech, and three raised pigmented lesions on the back. Her face was slightly coarse. Karyotype analysis on lymphocytes revealed a typical $46, \mathrm{XX}, \mathrm{r}(22)$ in all cells analysed. Examination of fibroblasts showed monosomy for chromosome 22 in $20 \%$ of cells. Using the ARSA probe, the breakpoint was located to $22 \mathrm{q} 13.3$, and the NF2 locus was intact. Full analysis of the NF2 gene in lymphocytes failed to reveal any abnormalities. Examination of meningioma tissue revealed two truncating mutations (531_560 del 29 and 1188 dup A), the first at a low level. However, there was clear evidence of loss of one copy of the NF2 gene by loss of heterozygosity analysis, consistent with loss of the ring.

\section{Case 4}

The early medical history was unremarkable with no evidence of learning disability. At the age of 18 years, he developed neurological signs due to a large left sided vestibular schwannoma. The tumour was treated surgically. In the medical record, the possibility of a small contralateral tumour was suggested. In retrospect, the first brain scan indeed showed bilateral disease (fig 2). Three years after surgical treatment, progression of the right sided tumour was noted and further treatment was given in the form of radiotherapy. Currently, the patient is doing well. MRI of the spinal cord has not been performed. Ophthalmological examination was normal.

Direct sequence analysis showed no differences between the patient's DNA and control samples for all 17 exons of the NF2 gene. The dosage results were consistent with the patient being mosaic for a deletion encompassing exons $1,4,8$, and 15 of the NF2 gene. The karyotype of the patient was 46,Y,der $(X)$ (22qter $\rightarrow$ q13 : Xp22.3 $\rightarrow$ Xqter), $\quad r(22)(p 13 \rightarrow q 13)$, as seen in fig 3 . This is an unbalanced translocation in which the terminal segment of the long arm of chromosome 22 (q13 $\rightarrow$ qter) has been translocated to the short arm of chromosome $X$, of which the terminal segment has been 


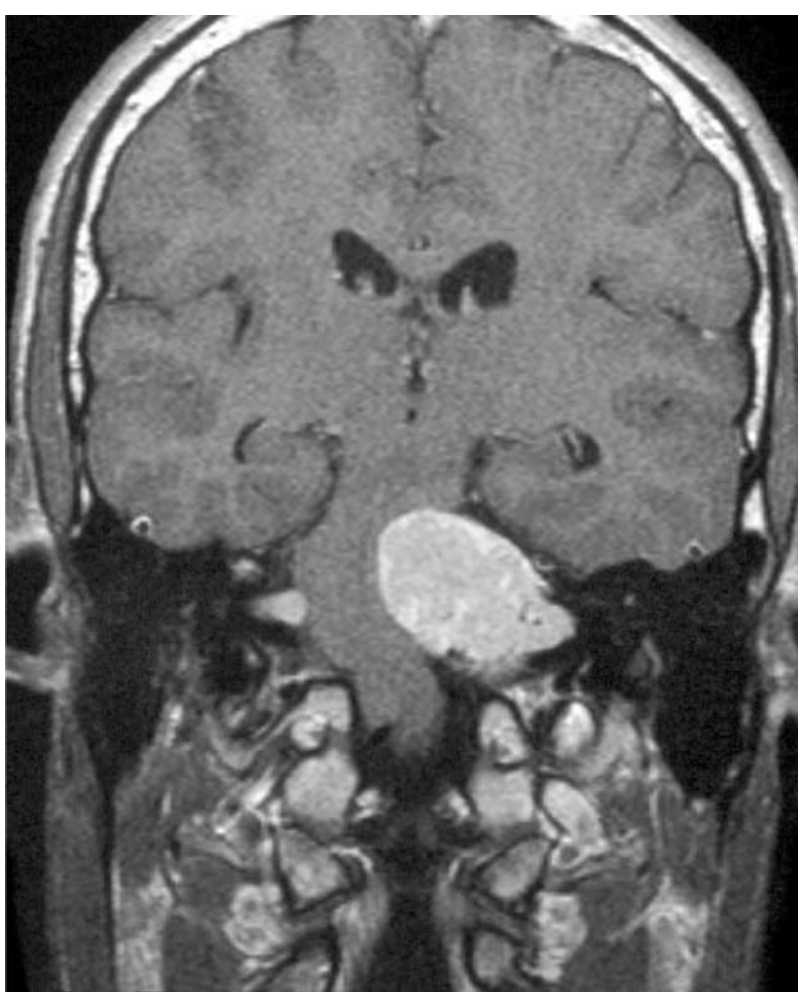

Figure 2 MRI brain scan of case 4, showing bilateral vestibular schwannoma.

deleted, and the remaining chromosome 22 has formed a ring.

FISH studies confirmed that the terminal segment of $\mathrm{X}$ was deleted, including the SHOX gene but not the STS locus. FISH studies also showed that the NF2 gene was present on the ring chromosome 22. Scoring of 56 cells showed that the ring with the NF2 gene was absent in four cells. Subsequent analysis of 71 G-banded cells showed that the unstable ring 22 was lost in one cell and manifested itself as a very small ring or a small acrocentric chromosome in 11 cells. This finding suggests that the NF2 gene may be missing in about $17 \%(12 / 71)$ of the blood lymphocytes and fits in with the DNA findings that showed mosaicism for the deletion of the NF2 gene.

As $\mathrm{X}$; autosome translocations in males are associated with infertility, the patient was referred for fertility studies. Azoospermia was found, but hormone studies were normal. Owing to the SHOX deficiency, radiological examination of the forearms and wrists were performed for signs of LériWeill dyschondrosteosis. There were no obvious clinical signs of SHOX deficiency (such as short stature), but $x$ ray examination of the forearms showed mild signs of LériWeil dyschondrosteosis (fig 4).

\section{Case 5}

Case 5 presented at the age of 7 years with skin nodules, which were removed and reported as neurofibromas. She was then lost to follow up but presented again at 20 years of age with a 1 year history of right temporal swelling and a 6 month history of bilateral hearing loss, unsteadiness, and frontal headaches. Cranial CT and MRI scans demonstrated a right cerebellopontine angle tumour, a right temporal meningioma, parafalcine meningiomatosis, and obstructive hydrocephalus. Spinal MRI demonstrated large extraspinal lesions in the paraspinal region on the left side. There were also several tiny lesions in the lumbar spine.

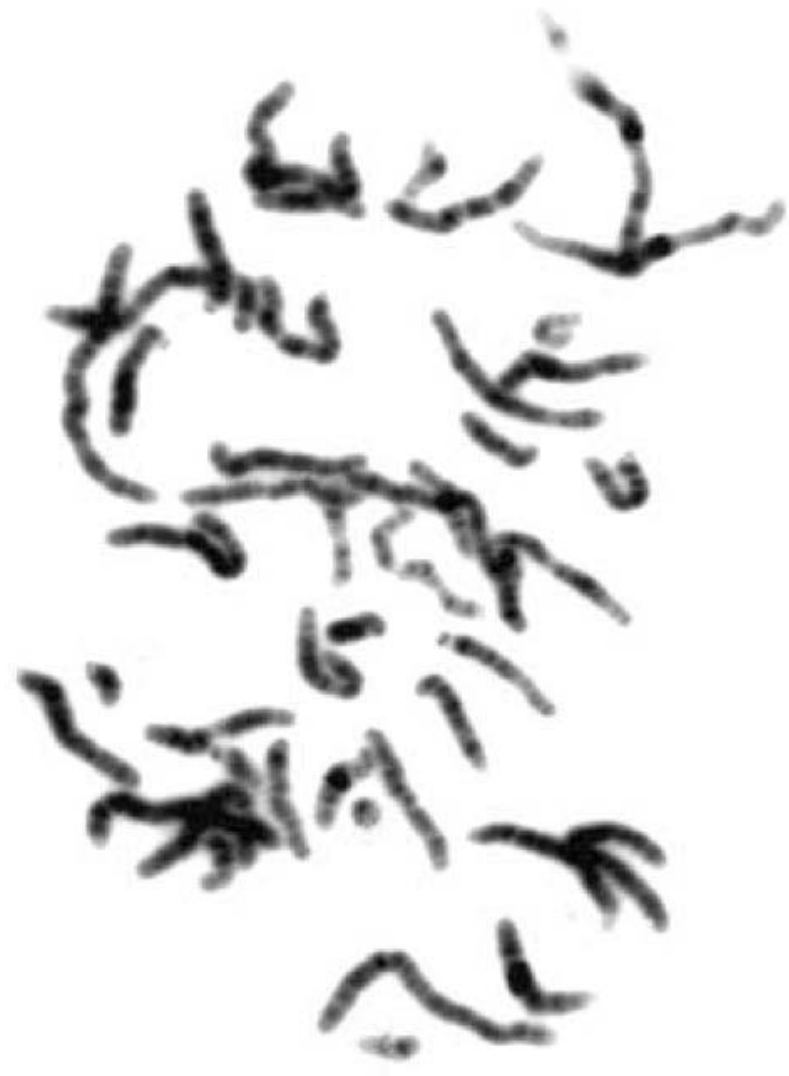

Figure 3 The metaphase of case 4 showing $46, Y, \operatorname{der}(X)(22 q$ ter $\rightarrow$ q13::Xp22.3 $\rightarrow$ Xqter), r(22)(p13 $\rightarrow$ q13). FISH analysis showed that the NF2 locus (green signal) was intact on the ring.

Over a period of 3 months, she underwent excision of the meningioma, subtotal excision of the right vestibular schwannoma, insertion of a V-P shunt, right lateral tarsorrhaphy, and C4-C5 laminectomy for partial excision of intra/ extradural schwannomas. She has subsequently developed marked proptosis of the right eye with exposure keratopathy and poor visual acuity. Her left eye also has substandard vision, although the reasons for this are not clear. Currently, at 24 years, she has a residual right vestibular schwannoma of $1.5 \mathrm{~cm}$ diameter, a left vestibular schwannoma of $0.5 \mathrm{~cm}$ diameter, and a recurrence of the right meningioma. She has poor vision bilaterally with slight residual hearing on the left side.

On initial discussion, there was no evidence of a family history of NF2. However, her father indicated that he had weakness in the right leg following a "chest infection", and his wife said that his hearing was deteriorating. MRI of the father demonstrated a left vestibular schwannoma of $15 \mathrm{~mm}$ diameter and a right vestibular schwannoma of $10 \mathrm{~mm}$ diameter. There was also an en plaque meningioma with

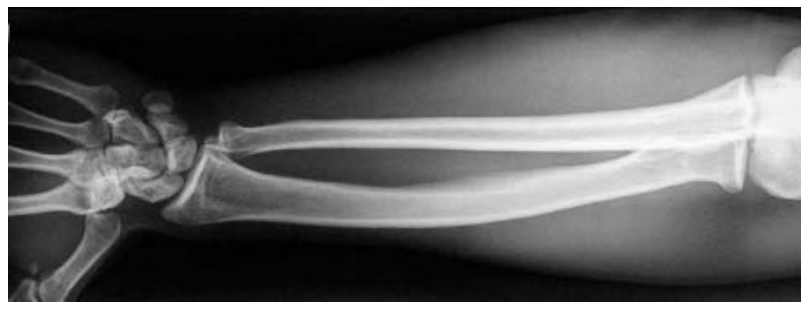

Figure $4 X$ ray examination of left forearm of case 4 showing mild signs of Léri-Weil dyschondrosteosis. 
other schwannomas on cranial nerves 9-11. Ventricular enlargement of a longstanding nature was also noted. A spinal MRI demonstrated further multiple lesions with enhancing lesions in the cervicomedullary junction, a meningeal lesion at $\mathrm{C} 7 / \mathrm{Tl}$, and further small lesions within the thoracic cord.

Lymphocyte DNA was screened for mutations in NF2 using SSCP/HA of the coding sequence and immediate splice donor and acceptor sites. No mutations were detected. Routine karyotyping of the proband demonstrated an apparently balanced translocation, 46,XX,t $(1 ; 22)(\mathrm{p} 36.1 ; \mathrm{q} 12)$, which was paternally inherited (the father was confirmed as having this). FISH studies using probes LL96C10 (located in the proximal region of NF2) and LL4D7 (located in the distal region of NF2) confirmed that the translocation had disrupted the NF2 gene (fig 5).

\section{Parental karyotypes}

The mother's karyotypes were normal for cases 1, 3, and 4 but other parental samples were unavailable.

\section{DISCUSSION}

We have described three different mechanisms involving large scale rearrangements of chromosome 22 that caused NF2 in five families. Three patients (cases 1-3) have the classical ring chromosome 22 with no involvement of another chromosome. The term "ring 22 syndrome" is not justified because there is extensive phenotypic variation among patients with ring chromosome 22. Affected individuals can demonstrate a wide variety of dysmorphic features ranging from mild and nonspecific to more marked and distinctive with developmental disabilities, behavioural problems, and mood disorders.

The only consistent feature is moderate to severe mental retardation. ${ }^{7}$ It is noteworthy that case 4 did not have any external, behavioural, or learning problems to suggest a ring chromosome disorder. The fact that the long arm of chromosome 22 was not deleted in any of the cells may explain why he had no other abnormalities and has normal intelligence. The $\mathrm{r}(22)$ in case 4 is different from other cases of $r(22)$ because the only apparent deletion in chromosome 22 is of the (genetically inactive) short arm.

Clinical features of neurofibromatosis or multiple meningiomas have been previously reported in patients with $\mathrm{r}(22)$ (table 1). ${ }^{8-12}$ Kehrer-Sawatzki et al ${ }^{8}$ suggested dividing $\mathrm{r}(22)$ patients into three groups: patients with NF2, those without NF2 but with multiple meningiomatosis, and those
Table 1 Clinical symptoms or meningiomatosis in published NF2 patients with $r(22)$

\begin{tabular}{|c|c|c|c|}
\hline Authors & Sex & $\begin{array}{l}\text { Age at } \\
\text { diagnosis }\end{array}$ & Clinical presentation \\
\hline Arinami et al ${ }^{9}$ & M & - & $\begin{array}{l}\text { Hearing loss, multiple } \\
\text { meningiomas }\end{array}$ \\
\hline Duncan et $a l^{10}$ & M & - & $\begin{array}{l}\text { Several peripheral } \\
\text { neurofibromas, including } \\
\text { plexiform neurofibroma }\end{array}$ \\
\hline Petrella et $a l^{11}$ & M & $\begin{array}{l}\text { Died at } \\
16 \text { years } \\
\text { of age }\end{array}$ & $\begin{array}{l}\text { Mental retardation, seizures, } \\
\text { multiple meningiomas }\end{array}$ \\
\hline Tommerup et al ${ }^{12}$ & M & - & $\begin{array}{l}\text { Mental retardation, peripheral } \\
\text { schwannomas, cerebellopontine } \\
\text { angle tumour (?VS), optic } \\
\text { atrophy, hearing loss }\end{array}$ \\
\hline $\begin{array}{l}\text { Kehrer-Sawatzki } \\
\text { et al }\end{array}$ & $\mathrm{F}$ & 38 years & $\begin{array}{l}\text { Bilateral vestibular } \\
\text { schwannomas, multiple } \\
\text { intracranial meningiomas, and } \\
\text { neurinomas }\end{array}$ \\
\hline
\end{tabular}

without features of either disease. Each of the classical $\mathrm{r}(22)$ patients in the present study have NF2.

About $90 \%$ of all NF2 patients develop bilateral vestibular schwannomas. ${ }^{1}$ Two different hypotheses have been proposed to explain the mechanism(s) of tumorigenesis in NF2 patients with $\mathrm{r}(22)$. The first hypothesis is based on the Knudson's "two-hit" model. ${ }^{13}$ Ring chromosomes are prone to loss during somatic mitoses. ${ }^{14}$ Therefore a constitutional mutation at the NF2 gene of the normal chromosome 22 (first hit) should result in tumour development if the resulting daughter cell becomes monosomic for chromosome 22 (second hit). The frequent loss of the ring chromosome during somatic mitoses also could explain the multiple sites of tumour development, although this may vary inter- and intra-individually. In reality the loss of the ring may be the initial event, as a few lymphocytes in every 50 are usually found to be monosomic for ring 22 in many patients, as confirmed in our own patients. It is likely therefore that these patients represent something similar to an NF2 patient who is mosaic for a whole gene deletion.

In contrast, Kehrer-Sawatzki et al ${ }^{8}$ suggested that the loss of a whole chromosome 22 might be more effective in triggering tumorigenesis than constitutional heterozygosity for a mutation that inactivates only the NF2 gene. This was based on the lack of convincing evidence for a pathogenic
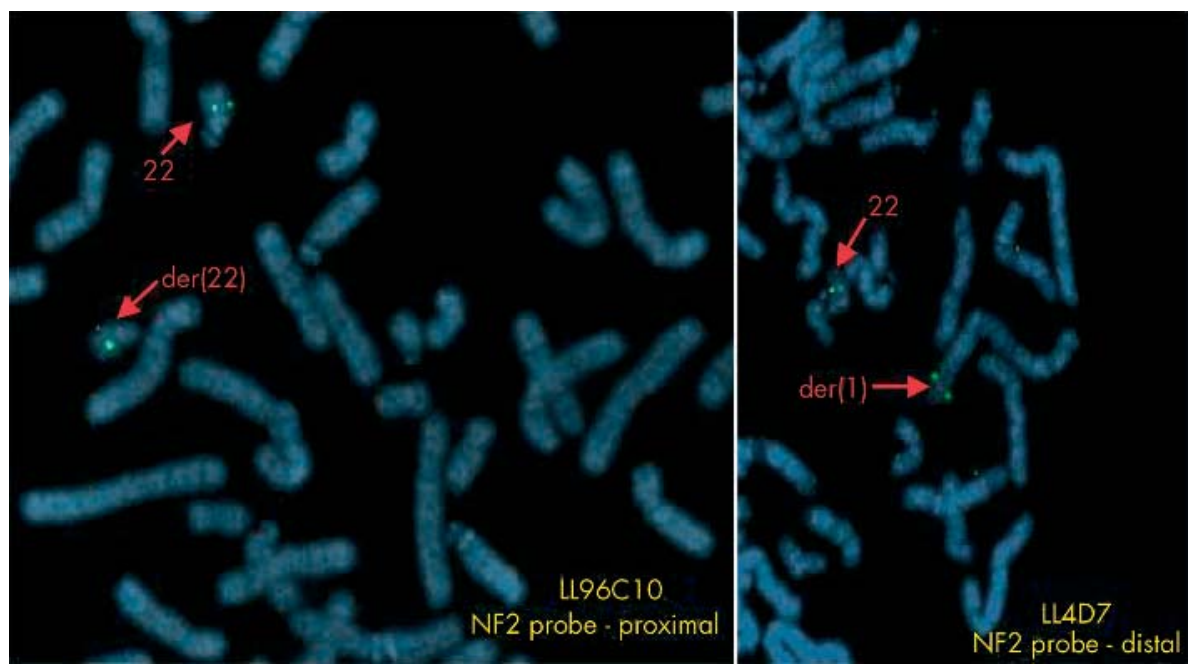

Figure 5 Karyotyping demonstrating an apparently balanced translocation, $46, X X, t(1 ; 22)(p 36.1 ; q 12)$ in case 5. FISH studies using probes LL96C10 (located in the proximal region of the NF2 gene) and LL4D7 (located in the distal region of the NF2 gene) confirmed that the translocation had disrupted the NF2 gene. 
constitutional mutation of the NF2 gene in their patient. This hypothesis may explain why these patients are more severely affected than a patient with a deletion of NF2 only, but our identification of mutations in NF2 in a meningioma from case 3 suggest that this gene is the primary target for somatic mutations. The absence of constitutional NF2 mutations as confirmed in our cases is unsurprising as the mitotically unstable ring 22 itself should be sufficient to predispose the tumours.

Chromosome 22 almost certainly harbours more tumour suppressor genes than NF2. ${ }^{15} 16$ This may be why some cases have multiple meningiomas and not the typical bilateral vestibular schwannomas of NF2. ${ }^{11}$ In addition to loss of NF2 in monosomy 22, other meningioma specific genes may be lost. Nonetheless, the meningioma in case 3 had clearly acquired somatic mutations in the NF2 gene. The presence of two separate truncating mutations suggests the presence of multifocal meningiomas, as we have previously described for vestibular schwannoma. ${ }^{17}$ Unfortunately tumour material was not available for the remaining patients. Therefore, case 3 still suggests that the inactivation of NF2 is the primary driving force behind tumour growth in $\mathrm{r}(22)$ patients. Many cases of $\mathrm{r}(22)$ were very young, and even at older ages, suggestive symptoms such as deafness may be overlooked in a mentally retarded patient. Many more of the previously reported young $\mathrm{r}(22)$ patients may go on to develop NF2 related tumours and may be mosaic for an NF2 deletion. A follow up assessment of individuals diagnosed as having r(22) should include full neurological examination and MRI scans.

Case 1 is the first documented case of NF2 with an $\mathrm{r}(22)$ who also developed a large diffuse goitre. The clinical features, together with the results of the clinical and the radiological studies, were not consistent with the diagnosis of Pendred's syndrome. True Pendred's syndrome should almost certainly be confined to patients who present with the classic clinical features along with positive perchlorate test, malformations of the inner ear, and PDS mutations. Pendred's syndrome is an autosomal recessive disorder. The genetic locus responsible for PS has recently been localised to $7 q 31$ and different mutations have been identified in an ion transport gene, making molecular diagnoses possible. ${ }^{18}$ As high resolution CT and MRI studies showed no alterations of the inner ear structures and there was no consistency with the clinical presentation of the hearing defect (audiometric testing early in childhood showed no hearing impairment), we did not perform a PDS genetic analysis. It seems likely, however, that the goitre and the $\mathrm{r}(22)$ are coincidental.

Case 4 has a complex unbalanced translocation. The occurrence of NF2 can be explained by the absence of the NF2 gene in some cells due to the instability of $\mathrm{r}(22)$. Indeed, case 4 showed enough monosomic cells to be defined as a mosaic deletion on dosage PCR. The NF2 phenotype in $\mathrm{r}(22)$ is similar to that of NF2 patients who are mosaic for other types of NF2 aberrations. ${ }^{19}{ }^{20}$ The fact that there is no deletion of the long arm of chromosome 22 in any of this patient's cells may explain why he has no other abnormalities and has normal intelligence.

The azoospermia in case 4 is related to the $\mathrm{X}$; autosome translocation. Male carriers of any X;autosome translocation are sterile, regardless of the position of the breakpoint in the $\mathrm{X}$ chromosome. The infertility is due to early cessation of germ cell maturation. Fourteen male carriers of X;autosome translocations were reviewed in 1983 and shown to be infertile. ${ }^{21}$ Three men with different X;autosome translocations were later identified and found to be infertile, two having documented azoospermia. ${ }^{22}$

Case 4 also had involvement of the SHOX locus that causes Léri-Weill dyschondrosteosis. The Léri-Weil syndrome was caused by the absence of the SHOX gene on the Xp. This condition is a dominantly inherited skeletal dysplasia, characterised by Madelung's deformity of the wrist, mesomelia, and short stature. Clinical expression varies between and within families. The clinical picture is generally more severe in females. In the majority of patients, deletions or point mutations of the SHOX gene have been documented. ${ }^{23}{ }^{24}$ It is notheworthy that case 4 would not have come to notice clinically unless he had developed NF2, and his subsequent $x$ rays confirmed features of Léri-Weill dyschondrosteosis.

A single case of a translocation resulting in disruption of the NF2 gene and clinical NF2 has been reported in the literature. ${ }^{25}$ Further characterisation showed that the breakpoint was within the intron between exons 14 and 15 of the NF2 gene. ${ }^{26}$ The father was said to be asymptomatic, although radiological investigations had not been undertaken. This case demonstrates the usefulness of FISH techniques to detect translocations through the NF2 gene. We have also confirmed 10 large deletions of NF2 using FISH techniques in about 200 NF2 families with identified genetic aberrations (DGR Evans, unpublished data). However, only 40 of the 340 NF2 families tested have had FISH analysis, and up to $10 \%$ of NF2 families could have genetic abnormalities that are detectable on FISH analysis.

A more recent report of a patient with NF2 and an X;22 translocation showed that the NF2 gene was not involved in the breakpoints, as shown by normal NF2 on FISH. However, aberrant X inactivation of the distal translocated long arm of chromosome 22 in the neural crest had led to inactivation of one copy of the NF2 gene as well as causing mental retardation. Interestingly, $100 \%$ of lymphocytes showed inactivation of the normal $X$ chromosome. ${ }^{27}$ Silencing of the NF2 gene by somatic methylation is now being recognised, ${ }^{28}$ but this recent report shows that silencing due to an inherited abnormality is possible, albeit by mechanisms that have occurred somatically. This mechanism would obviously not account for NF2 in case 4 because X chromosome inactivation would not normally occur in a male.

Previous studies of genotype-phenotype correlations in NF2 have demonstrated that, in general, missense mutations (which result in a complete protein product) and large deletions (which result in an absent protein) each cause mild disease, whilse protein truncating mutations cause severe disease. ${ }^{4-6}$ It is interesting that both case 5 with a balanced translocation and the previous report of a translocation each have severe disease. A translocation should result in absent protein, perhaps then resulting in less severe disease. In each case, the daughter was symptomatically worse than the father, although there is not a substantial gender difference in NF2 $2{ }^{29}$ It is possible that the translocation of the $3^{\prime}$ end of another gene onto NF2 could allow protein translation, and the translocation could therefore "mimic" the effects of a truncating mutation.

\section{CONCLUSIONS}

Major chromosomal rearrangements involving chromosome 22 can cause NF2 even if the NF2 locus itself is intact. Ring chromosome 22 patients are variably predisposed to NF2 related tumours and other anomalies, including mental retardation. In view of the notable prevalence of deletions detected by FISH, chromosomal analysis including FISH can be a useful first step in assessment of the NF2 locus, even in patients without mental retardation.
Authors' affiliations
T Tsilchorozidou, J G Yovos, Department of Endocrinology, Diabetes and Metabolism, AHEPA University Hospital, Thessaloniki, Greece F H Menko, K Madan, Department of Clinical Genetics and Human Genetics, VU University Medical Center, Amsterdam, the Netherlands 
F Lalloo, P Smith, A Malcolmson, J Dore, A J Wallace, D G R Evans, Academic Unit of Medical Genetics and Regional Genetics Service, St. Mary's Hospital, Manchester, UK

R De Silva, H Thomas, Department of Neurology, Oldchurch Hospital, Romford, Essex, UK

M Tsaligopoulos, Department of Otorhinolarygology and Hearing Impairment, AHEPA University Hospital, Thessaloniki, Greece

N Vogiatzis, Department of Paediatrics and Medical Genetics, AHEPA University Hospital, Thessaloniki, Greece

A Kidd, A Brown, Department of Medical Genetics, Wellington Hospital, Wellington, New Zealand

Conflict of interest: none declared

Correspondence to: Professor D G R Evans, Academic Unit of Medical Genetics and Regional Genetics Service, St. Mary's Hospital,

Manchester M13 OJH, UK; gareth.evans@cmmc.nhs.uk

Revised version received 19 December 2003

Accepted for publication 19 December 2003

\section{REFERENCES}

1 Evans DGR, Huson SM, Donnai D, Neary W, Blair V, Newton V, Harris R. A clinical study of type 2 neurofibromatosis. Q J Med 1992;84:603-18.

2 Trofatter JA, MacCollin MM, Rutter JL, Murrell JR, Duyao MP, Eldridge R, Kley N, Menon AG, Pulaski K, Haase VH, Ambrose CM, Munroe D, Bove C, Haines JL, Martuza RL, MacDonald ME, Seizinger BR, Short PM, Buckler AJ Gusella JF. A novel moesin-, ezrin-, radixin-like gene is a candidate for the neurofibromatosis 2 tumor suppressor. Cell 1993;72:791-800.

3 Rouleau GA, Merel P, Lutchman M, Sanson M, Zucman J, Marineau C, Hoang-xuan K, Demczuk S, Desmaze C, Plougastel B, Pulst SM, Lenoir G, Biilsma E, Fashold R, Dumanski J, de Jong P, Parry D, Eldridge R, Aurias A Delattre $O$, Thomas $G$. Alteration in a new gene encoding a putative membrane-organizing protein causes neuro-fibromatosis type 2. Nature 1993;363:515-21.

4 Parry DM, MacCollin M, Kaiser-Kupfer MI, Pulaski K, Nicholson HS, Boleseta M, Eldridge R, Gusella JF. Germ-line mutations in the neurofibromatosis 2 gene: correlations with disease severity and retinal abnormalities. Am J Hum Genet 1996;59:529-39.

5 Evans DGR, Trueman L, Wallace A, Mason S, Strachan T. Genotype/ phenotype correlations in type 2 neurofibromatosis: evidence for more severe disease with truncating mutations. J Med Genet 1998;35:450-5.

6 Evans DGR, Sainio M, Baser ME. Neurofibromatosis type 2. J Med Genet 2000;37:897-904.

7 Ishmael HA, Cataldi D, Begleiter ML, Pasztor LM, Dasouki MJ, Butler MG. Five new subjects with ring chromosome 22. Clin Genet 2003:63:410-14.

8 Kehrer-Sawatki H, Udart M, Krone W, Baden R, Fahsold R, Thomas G Schmucker B, Assum G. Mutational analysis and expression studies of the neurofibromatosis type 2 (NF2) gene in a patient with ring chromosome 22 and NF2. Hum Genet 1997;100:67-74.

9 Arimani T, Hayashi N, Nagase H, Ogawa M, Nakamura Y. Multifocal meningiomas in a patient with a constitutional ring chromosome 22. J Med Genet 1986;23:178-80.

10 Duncan AMV, Partington MW, Soudek D. Neurofibromatosis in a man with a ring chromosome 22: in situ hybridization studies. Cancer Genet Cytogenet 1987;25:169-74.
11 Petrella $\mathbf{R}$, Levine S, Wilmot PL, Ashar KD Casamassima AC, Shapiro IR. Multiple meningiomas in a patient with a constitutional ring chromosome 22. Am J Med Genet 1993;47:184-6.

12 Tommerup N, Warburg M, Gieselmann V, Hansen BR, Koch J, Petersen GB. Ring chromosome 22 and neurofibromatosis. Clin Genet 1992;42:171-7.

13 Knudson AG. Mutation and cancer: statistical study of retinoblastoma. Proc Natl Acad Sci USA 1971;68:820-3.

14 Kistenmacher ML, Punnett HH. Comparative behaviour of ring chromosomes. Am J Hum Genet 1970;22:304-18.

15 Pulst SM, Rouleau GA, Marineau C, Fain P, Sieb JB. Familial meningioma is not allelic to neurofibromatosis 2. Neurology 1993;43:2096-8.

16 Zucman-Rosi J, Legoix P, Thomas G. Identification of new members of the Gas2 and Ras families in the 22q12 chromosome region. Genomics 1996;38:247-54.

17 Mohyuddin A, Neary W, Wallace A, Wu CL, Black G, Purcell S, Reid H, Ramsden RT, Read A, Evans DGR. Molecular genetic analysis of the NF2 gene in young patients with unilateral vestibular schwannomas. J Med Genet 2002;39:311-15

18 Everett LA, Glaser B, Beck JK. Pendred syndrome is caused by mutations in a putative sulphate transporter gene (PDS). Nat Genet 1997;17:411-22.

19 Evans DGR, Wallace A, Trueman L, Wu C-L, Ramsden RT, Strachan T. Mosaicism in classical neurofibromatosis type 2: a common mechanism for sporadic disease in tumor prone syndromes? Am J Hum Genet 1998;63:727-36.

20 Kluwe L, Mautner VF, Heinrich B, Dezube R, Jacoby LB, Friedrich RE, MacCollin M. Molecular study of frequency of mosaicism in neurofibromatosis 2 patients with bilateral vestibular schwannomas. J Med Genet 2003:40:109-14.

21 Madan K. Balanced structural changes involving the human X: effect on sexual phenotype. Hum Genet 1983;63:216-21.

22 Kalz-Füller B, Sleegers E, Schwanitz G, Shubert R. Characterisation, phenotypic manifestations and $X$-inactivation pattern in 14 patients with X-autosome translocations. Clin Genet 1999;55:362-6.

23 Ross JL, Scott Jr C, Marttila P, Kowal K, Nass A, Papenhausen P, Abboudi J, Osterman L, Kushner H, Carter P, Ezaki M, Elder F, Wei F, Chen H, Zinn AR. Phenotypes associated with SHOX deficiency. J Clin Endocrinol Metab 2001;86:5674-80.

24 Schiller S, Spranger S, Schechinger B, Fukami M, Merker S, Drop SL, Troger J, Knoblauch H, Kunze J, Seidel J, Rappold GA. Phenotypic variation and genetic heterogeneity in Léri-Weill syndrome. Eur J Hum Genet 2000;8:54-62.

25 Arai E, Ikeuchi T, Karasawa S, Tamura A, Yamamoto K, Kida M, Ichimura K, Yuasa $Y$, Tonomura A. Constitutional translocation $t(4,22)$ (q12; 1 2.2) associated with neurofibromatosis type 2. Am J Med Genet 1992;44:163-7.

26 Arai E, Ikeuchi T, Nakamura Y. Characterisation of the translocation breakpoint on 22q12.2 in a patient with neurofibromatosis type 2 (NF2). Hum Mol Genet 1994;3:937-9.

27 Bovie C, Holden ST, Schroer A, Smith E, Trump D, Raymond FL. Neurofibromatosis 2 in a patient with a de novo balanced reciprocal translocation 46,X,t(X;22)(p1 1.2;q1 1.2). J Med Genet 2003;40:682-4.

28 Kino T, Takeshima H, Nakao M, Nishi T, Yamamoto K, Kimura T, Saito $Y$, Kochi M, Kuratsu J, Saya H, Ushio Y. Identification of the cis-acting region in the NF2 gene promoter as a potential target for mutation and methylation-dependent silencing in schwannoma. Genes Cells 2001;6:441-54

29 Evans DGR, Blair V, Strachan T, Lye RH, Ramsden RT. Variation in expression of the gene for type 2 neurofibromatosis: absence of a gender effect on vestibular schwannoma. J Laryngol Otol 1995;9:830-5. 